\title{
Papers
}

\section{Will new diagnostic criteria for diabetes mellitus change phenotype of patients with diabetes? Reanalysis of European epidemiological data}

\author{
DECODE Study Group on behalf of the European Diabetes Epidemiology Study Group
}

\begin{abstract}
Objective: To evaluate the impact of the revised diagnostic criteria for diabetes mellitus adopted by the American Diabetes Association on prevalence of diabetes and on classification of patients. For epidemiological purposes the American criteria use a fasting plasma glucose concentration $\geqslant 7.0 \mathrm{mmol} / \mathrm{l}$ in contrast with the current World Health Organisation criteria of 2 hour glucose concentration $\geqslant 11.1 \mathrm{mmol} / \mathrm{l}$. Design: Data were collected from 13 populations and three occupational based studies from eight European countries. All studies used a $75 \mathrm{~g}$ oral glucose tolerance test to measure fasting and 2 hour glucose concentrations.
\end{abstract}

Subjects: 17881 men; 8309 women; age range 17-92 years.

Main outcome measures: Classification of diabetes according to both sets of criteria.

Results: The application of the American criteria on European populations induced changes in prevalence of diabetes ranging from a reduction of $4.0 \%$ to an increase of $13.2 \%$. A total of 1517 previously undiagnosed individuals had diabetes according to either the WHO or the American criteria. Among 1044 with diabetes according to American criteria, only $45 \%$ had 2 hour values fulfilling the WHO criteria. The risk of disagreement of classification decreased with increasing body mass index $(\mathrm{P}<0.00001)$ and increasing age $(\mathrm{P}<0.0001)$; the impact of sex was not significant $(\mathrm{P}=0.08)$.

Conclusions: This shift in strategy from using 2 hour to fasting plasma glucose will cause an increase in the prevalence of diabetes in some European populations. A high degree of disagreement in the classification was observed between the two recommendations. Prospective data are needed to evaluate whether the WHO or the American criteria best identify individuals at risk of developing microvascular complications and cardiovascular disease. Wider implementation of revised diagnostic criteria should await prospective data.

\section{Introduction}

Commonly accepted diagnostic criteria for diabetes mellitus were developed by the National Diabetes Data
Group in $1979^{1}$ and the World Health Organisation (WHO) in $1980^{2}$ and updated in $1985 .^{3}$ During its annual meeting in 1997, the American Diabetes Association (ADA) approved new diagnostic criteria for diabetes mellitus on the basis of recommendations from an expert committee on the diagnosis and classification of diabetes mellitus. ${ }^{4}$ On the basis of data from three different populations the intention was to identify the fasting blood glucose concentration that best predicted the risk of developing microvascular complications. ${ }^{4}$ The revised criteria are symptoms of diabetes and a casual plasma glucose concentration $\geqslant 11.1 \mathrm{mmol} / \mathrm{l}$ or a fasting plasma glucose $\geqslant 7.0 \mathrm{mmol} / \mathrm{l}$ or 2 hour plasma glucose $\geqslant 11.1 \mathrm{mmol} / \mathrm{l}$ during a standard $75 \mathrm{~g}$ oral glucose tolerance test (as previously recommended by the $\mathrm{WHO}^{3}$ ).

For clinical diagnosis the American Diabetes Association recommended that the diagnosis should be confirmed by a second test, while for epidemiological studies they recommended the use of fasting plasma glucose $\geqslant 7.0 \mathrm{mmol} / \mathrm{l}$ alone. It was stated that this approach would lead to slightly lower estimates of prevalence of diabetes than the use of 2 hour glucose according to the WHO criteria. ${ }^{4}$ The WHO Study Group gave both fasting and 2 hour glucose criteria for the diagnosis (fasting $\geqslant 7.8$ and 2 hour $\geqslant 11.1 \mathrm{mmol} / \mathrm{l}$ ), but for epidemiological and screening purposes they stated that the 2 hour value could be used alone, a recommendation followed in most epidemiological studies.

Diabetes mellitus is one of the most common chronic diseases and is a major contributor to the development of cardiovascular disease. ${ }^{5}$ The prevalence of non-insulin dependent diabetes mellitus has increased dramatically over the past decades, ${ }^{6}$ predominantly because of changes in lifestyle, increasing prevalence of obesity, and ageing of populations. ${ }^{7}$ The estimated worldwide number of people with diabetes is over 100 million, and in Europe the cost of treating diabetes and its complications has been estimated to be $5.8 \%$ of the total healthcare budget. ${ }^{8}$

Any change in diagnostic criteria may not only affect the accepted prevalence of diabetes but may also result in a reclassification of individuals. Individuals with diabetes according to the WHO criteria may not be classified as having diabetes according to the new

\section{Editorial by Wareham and O'Rahilly \\ Members of the group are listed at the end of the paper \\ Correspondence to: Dr Knut Borch-Johnsen, Steno Diabetes Centre, Niels Steensens Vej 2, DK 2820 Gentofte, Denmark kbjo@novo.dk \\ BMJ 1998;317:371-5}


Table 1 Prevalence of known diabetes. Total prevalence according to WHO and ADA criteria, and change in prevalence for 16 European populations

\begin{tabular}{|c|c|c|c|c|}
\hline \multirow[b]{2}{*}{ Study centre } & \multicolumn{3}{|c|}{ Prevalence of diabetes $(\%)$} & \multirow{2}{*}{$\begin{array}{c}\text { Change in } \\
\text { prevalence } \\
(95 \% \mathrm{CI})\end{array}$} \\
\hline & Known & WHO criteria* & ADA criteria† & \\
\hline Uppsala, Sweden $(n=1181)$ & 5.9 & 15.1 & 11.1 & $-4.0(-7.1$ to -0.6$)$ \\
\hline Glostrup, Denmark ( $\mathrm{n}=2109)$ & 6.4 & 12.8 & 10.2 & $-2.6(-4.7$ to 0.6$)$ \\
\hline POL-MONICA, Krakow $(n=364)$ & 1.4 & 5.8 & 4.1 & $-1.7(-3.9$ to 0.5$)$ \\
\hline East and West Finland $(n=411)$ & 13.9 & 21.9 & 20.7 & $-1.2(-7.8$ to 5.1$)$ \\
\hline Zutphen study, Netherlands $(\mathrm{n}=485)$ & 8.0 & 15.4 & 14.6 & $-0.8(-5.7$ to 4.1$)$ \\
\hline Cremona study, Italy $(n=1818)$ & 8.0 & 10.5 & 9.8 & $-0.7(-2.8$ to 1.4$)$ \\
\hline TELECOM, France $(n=3875)$ & 0.2 & 1.0 & 0.6 & $-0.4(-0.7$ to 1.9$)$ \\
\hline Hoorn study, Netherlands $(\mathrm{n}=2468)$ & 3.6 & 8.1 & 8.5 & $0.4(-1.2$ to 2.0$)$ \\
\hline Helsinki policemen study, Finland ( $\mathrm{n}=1136)$ & 1.4 & 2.3 & 2.9 & $0.6(-0.7$ to 1.9$)$ \\
\hline Pieksamaki, Finland $(\mathrm{n}=513)$ & - & 2.5 & 3.5 & $1.0(-1.2$ to 3.1$)$ \\
\hline FIN-MONICA, Finland $(n=2051)$ & 4.3 & 6.2 & 7.2 & $1.0(-0.6$ to 2.6$)$ \\
\hline Paris prospective study $(n=7176)$ & 2.0 & 4.2 & 5.4 & $1.2(0.4$ to 1.8$)$ \\
\hline Newcastle heart project $(n=824)$ & 2.7 & 6.2 & 8.9 & $2.7(0.0$ to 5.3$)$ \\
\hline Oulu, Finland $(\mathrm{n}=891)$ & 4.0 & 7.7 & 11.8 & 4.1 (1.0 to 7.3$)$ \\
\hline Vantaa, Finland $(\mathrm{n}=609)$ & 9.5 & 18.5 & 24.3 & $5.8(0.5$ to 10.9$)$ \\
\hline Oulu elderly, Finland $(n=379)$ & 17.2 & 25.9 & 39.1 & 13.2 (5.1 to 21.3 ) \\
\hline Overall & 3.7 & 7.2 & 7.7 & $0.5(0.3$ to 0.8$)$ \\
\hline
\end{tabular}

*WHO criteria: known diabetes or diabetes defined by 2 hour glucose ( $\geqslant 11.1 \mathrm{mmol} / \mathrm{l})$.

†American Diabetes Association (ADA) criteria: known diabetes or diabetes defined by fasting glucose $(\geqslant 7.0 \mathrm{mmol} / \mathrm{l})$.

ADA criteria and vice versa. We evaluated the impact of the new diagnostic criteria on the prevalence of diabetes and classification of individuals on the basis of data from epidemiological surveys carried out in European countries with the standard glucose tolerance test.

\section{Subjects and methods}

Centres in Europe that had performed population based studies or studies in large representative samples of occupational groups on the prevalence of diabetes mellitus in adults were invited to participate. We identified 13 population based studies ${ }^{9-21}$ and three studies in occupational groups. ${ }^{22-24}$ All centres used a $75 \mathrm{~g}$ glucose load. Only individuals with both fasting and 2 hour glucose values or with previously known diabetes were included.

Table 2 Basic characteristics of European populations included in DECODE study

\begin{tabular}{lccccc} 
Study centre & $\begin{array}{c}\text { No of } \\
\text { men }\end{array}$ & $\begin{array}{c}\text { No of } \\
\text { women }\end{array}$ & $\begin{array}{c}\text { Age } \\
\text { (years) }\end{array}$ & $\begin{array}{c}\text { Mean (SD) } \\
\text { body mass } \\
\text { index(kg/m }{ }^{2} \text { ) }\end{array}$ & $\begin{array}{c}\text { Blood } \\
\text { sampled }\end{array}$ \\
\hline Uppsala, Sweden & 1181 & 0 & $69-73$ & $26.3(3.4)$ & Plasma \\
\hline Glostrup, Denmark & 1071 & 1038 & $39-70$ & $24.7(4.0)$ & Whole \\
\hline POL-MONICA, Krakow & 172 & 192 & $43-73$ & $28.0(4.8)$ & Plasma \\
\hline East and West Finland & 411 & 0 & $69-89$ & $26.4(3.8)$ & Plasma \\
\hline Zutphen study, Netherlands & 485 & 0 & $69-90$ & $25.5(3.1)$ & Plasma \\
\hline Cremona study, Italy & 804 & 1014 & $40-88$ & $26.6(4.4)$ & Plasma \\
\hline TELECOM, France & 1927 & 1948 & $17-75$ & $23.6(3.4)$ & Plasma \\
\hline Hoorn study, Netherlands & 1137 & 1331 & $49-77$ & $26.6(3.6)$ & Plasma \\
\hline Helsinki policemen study, Finland & 1136 & 0 & $30-69$ & $25.7(2.8)$ & Whole \\
\hline Pieksamaki, Finland & 249 & 264 & $31-52$ & $28.2(4.8)$ & Whole \\
\hline FIN-MONICA, Finland & 937 & 1114 & $45-64$ & $27.5(4.4)$ & Plasma \\
\hline Paris prospective study & 7176 & 0 & $44-55$ & $26.0(3.3)$ & Plasma \\
\hline Newcastle heart project & 430 & 394 & $27-76$ & $26.4(4.5)$ & Plasma \\
\hline Oulu, Finland & 348 & 443 & 55 & $26.6(3.9)$ & Capillary \\
\hline Vantaa, Finland & 276 & 333 & $71-72$ & $27.2(4.3)$ & Whole \\
\hline Oulu Elderly, Finland & 141 & 238 & $70-92$ & $28.2(4.5)$ & Capillary \\
\hline Overall & 17881 & 8309 & $17-92$ & $25.9(3.9)$ & \\
\hline
\end{tabular}

*Venous plasma blood, venous whole blood, or capillary whole blood.
From each centre crude original data on sex, age, height, weight, status of known diabetes, and fasting and 2 hour blood glucose concentrations as well as mode of recruitment, number invited, number participating, exclusion criteria for oral glucose tolerance test, date of the start and end of survey, time of day of blood sampling, glucose load, blood specimen used (venous whole blood, venous plasma, capillary whole blood), and the method of glucose assay were sent to the diabetes and genetic epidemiology unit of the National Public Health Institute in Helsinki, Finland. For subjects known to have diabetes, information was collected on how their diabetes was assessed. Data were analysed for each centre individually and thereafter a combined analysis was performed.

To compare the criteria from WHO and ADA we used the recommendations for epidemiological surveys ${ }^{3}{ }^{4}$ : 2 hour post-load glucose and fasting values, respectively. As different methods for blood glucose measurement were used (table 1), glucose data could not be pooled. All individuals were classified on the basis of fasting venous plasma glucose concentration as ADA non-diabetic (fasting plasma glucose $<7 \mathrm{mmol} / \mathrm{l}$ ) or ADA diabetic (fasting plasma glucose $\geqslant 7.0 \mathrm{mmol} / \mathrm{l}$ ) and on the basis of the 2 hour value as WHO non-diabetic (2 hour plasma glucose $<11.1 \mathrm{mmol} / \mathrm{l}$ ) or WHO diabetic (2 hour plasma glucose $\geqslant 11.1 \mathrm{mmol} / \mathrm{l})$. Corresponding cut off points for venous whole blood were fasting blood glucose $<6.1$ versus $\geqslant 6.1 \mathrm{mmol} / 1$ and 2 hour blood glucose $<10.0$ versus $\geqslant 10.0 \mathrm{mmol} / \mathrm{l}$, and for capillary whole blood the cut off points were fasting capillary glucose $<6.1$ versus $\geqslant 6.1 \mathrm{mmol} / 1$ and 2 hour values $<11.1$ and $\geqslant 11.1 \mathrm{mmol} /$.

Table 2 shows the basic characteristics of the 16 study populations. A total of 26190 individuals were included in the present study (17881 men). For the analysis of the disagreement in classification between the WHO and ADA criteria only individuals without known diabetes were included.

All analyses were performed at the National Public Health Institute in Helsinki with sPss version 7.5.1 for Windows.

\section{Results}

Prevalence of diabetes-Figure 1 shows the prevalence of diabetes according to the WHO and ADA criteria. Both sets of criteria included previously diagnosed diabetic individuals as diabetic, regardless of their glucose concentration. In six studies the prevalence was lower with the ADA criteria than with the WHO criteria, while in 10 studies it was higher with the ADA than with the WHO criteria. The difference in prevalence with these two criteria ranged from $-4.0 \%$ to $13.2 \%$ and the overall difference was $0.5 \%$ (see table 1).

Disagreement of classification between criteria for previously undiagnosed diabetes - A total of 1517 individuals had diabetes according to either the ADA or the WHO criteria. Among 904 who had diabetes according to the WHO criteria, $473(52 \%)$ had a fasting plasma glucose concentration $(<7.0 \mathrm{mmol} / \mathrm{l})$ that did not indicate diabetes (table 3 and figure 2). Among 1044 who had diabetes according to the ADA criteria, $59 \%$ failed to 
reach the 2 hour glucose diagnostic value for diabetes $(\geqslant 11.0 \mathrm{mmol} / \mathrm{l})$.

Factors associated with disagreement of classificationTable 4 shows the degree of disagreement in the diagnostic classification between the WHO and the ADA criteria according to age, sex, and body mass index. No significant difference was found for sex. Age was significantly associated with the probability of disagreement. Individuals below age 65 years were more likely to be diagnosed on the basis of the ADA criteria than on the basis of the WHO criteria $(\mathrm{P}<0.0001)$. Lean individuals were more likely to have a high post-load glucose values, while overweight and obese individuals (body mass index $\geqslant 25 \mathrm{~kg} / \mathrm{m}^{2}$ ) were more likely to have diagnostic fasting plasma glucose values $(\mathrm{P}<0.00001)$.

\section{Discussion}

One main reason for revising the diagnostic criteria for diabetes mellitus has been an intention to simplify the diagnosis of the disease, as epidemiological surveys show that $30 \%$ to $60 \%$ of all diabetic individuals in the community are undiagnosed. ${ }^{625}$ Even when patients have no symptoms of hyperglycaemia the risk of cardiovascular disease in this group is doubled, and $10-21 \%$ will have microvascular complications (retinopathy, nephropathy, or neuropathy) by the time diabetes is diagnosed..$^{25}$ Early detection of diabetes is preferable as microvascular complications are prevent-

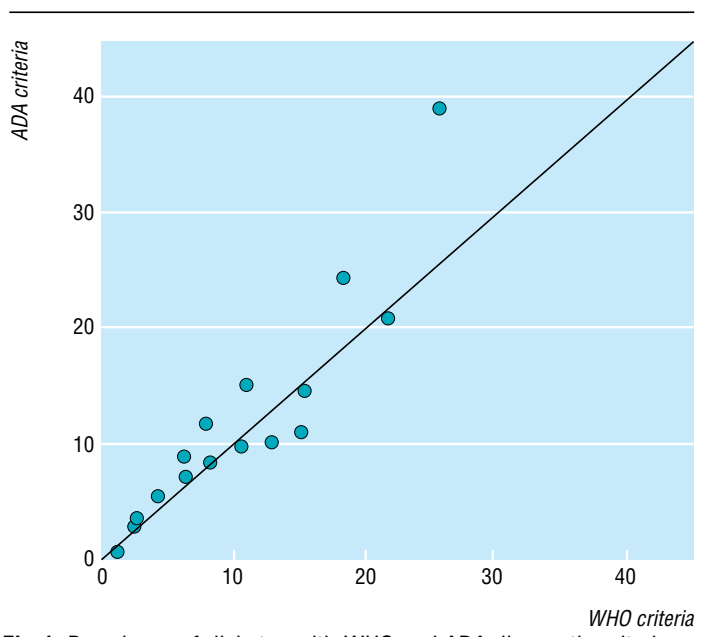

Fig 1 Prevalence of diabetes with WHO and ADA diagnostic criteria in 16 European populations

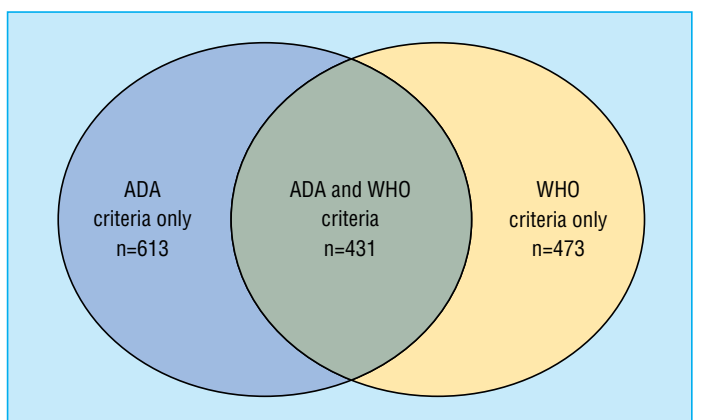

Fig 2 Overlap between individuals diagnosed as diabetic according to fasting plasma glucose concentration (ADA criteria) or the 2 hour glucose value (WHO criteria)
Table 3 Prevalence of diabetes defined by fasting or 2 hour glucose concentrations for all subjects not previously identified as diabetic

\begin{tabular}{|c|c|c|c|}
\hline \multirow[b]{2}{*}{ Fasting glucose concentrations ( $\mathrm{mmol} / \mathrm{l}$ ) } & \multicolumn{2}{|c|}{2 hour glucose concentration (mmol/l) } & \multirow[b]{2}{*}{ Total } \\
\hline & $<11.1$ & $\geqslant 11.1$ & \\
\hline$<7.0$ & 23702 & 473 & 24175 \\
\hline$\geqslant 7.0$ & 613 & 431 & 1044 \\
\hline Total & 24315 & 904 & 25219 \\
\hline
\end{tabular}

Table 4 Characteristics of previously undiagnosed subjects identified as diabetic according to WHO and ADA criteria for diagnosis of diabetesy. Figures are numbers (percentages) of subjects

\begin{tabular}{|c|c|c|c|c|}
\hline Variable & $\begin{array}{l}\text { WHO criteria* } \\
\text { only }(n=473)\end{array}$ & $\begin{array}{l}\text { ADA criteriat only } \\
(\mathrm{n}=613)\end{array}$ & $\begin{array}{l}A D A \text { and } W H O \\
\text { criteria }(n=431)\end{array}$ & P value \\
\hline \multicolumn{5}{|l|}{ Sex: } \\
\hline Men $(n=1048)$ & $310(30)$ & $427(41)$ & $311(30)$ & \multirow{2}{*}{0.08} \\
\hline Women $(n=469)$ & $164(35)$ & $185(39)$ & $120(26)$ & \\
\hline \multicolumn{5}{|l|}{ Age (years): } \\
\hline$<50(n=414)$ & $144(35)$ & $176(42)$ & $94(23)$ & \multirow{3}{*}{0.0001} \\
\hline $50-64(n=492)$ & $130(26)$ & $234(48)$ & $128(26)$ & \\
\hline$\geqslant 64(n=611)$ & $199(33)$ & $203(33)$ & $209(34)$ & \\
\hline \multicolumn{5}{|c|}{ Body mass index $\left(\mathrm{kg} / \mathrm{m}^{2}\right) \S:$} \\
\hline$<25(n=345)$ & $170(49)$ & $125(36)$ & $50(14)$ & \multirow{3}{*}{0.00001} \\
\hline $25-30(n=672)$ & $189(28)$ & $271(40)$ & $212(32)$ & \\
\hline$\geqslant 30(\mathrm{n}=484)$ & $108(22)$ & $211(44)$ & $165(34)$ & \\
\hline
\end{tabular}

*WHO criteria: diabetes defined by 2 hour glucose $\geqslant 11.1 \mathrm{mmol} / \mathrm{l}$.

†ADA criteria: diabetes defined by fasting glucose $\geqslant 7.0 \mathrm{mmol} / \mathrm{l}$.

$\ddagger \chi^{2}$ test.

$\S$ Missing for 16 .

able through strict glycaemic control $^{26}{ }^{27}$; the prevalence of modifiable cardiovascular risk factors such as dyslipidaemia and hypertension is high ${ }^{24}$; ; and early diagnosis and treatment of retinopathy and nephropathy is essential to prevent blindness and end stage renal failure. The American Diabetes Association argues that fasting blood glucose is easier and cheaper to determine than the glucose tolerance test and should therefore replace it for diagnostic purposes. The present study, however, shows that a change in diagnostic procedure is not a simple issue.

\section{Prevalence and classification}

Analysing the impact of revising the diagnostic criteria, we found that the overall change in the prevalence of diabetes was $0.5 \%$ but with substantial variation between the populations studied. Our estimate is conservative, accounting only for the change in prevalence related to previously undiagnosed cases and assuming no effect of the new criteria on known cases of diabetes.

Another and far more important consequence of the adoption of the ADA criteria is that the diabetic status of a large number of individuals will be changed. This disagreement in classification goes in both directions, from diabetes to normal and from normal to diabetes. Among individuals with diabetes according to the ADA criteria but a 2 hour post-load value below $11.1 \mathrm{mmol} / \mathrm{l}$, the median 2 hour blood glucose was $8.0 \mathrm{mmol} / \mathrm{l}$ and for individuals with a 2 hour value of $\geqslant 11 \mathrm{mmol} / 1$ and a fasting value of $<7.0 \mathrm{mmol} / \mathrm{l}$, the median fasting value was $6.0 \mathrm{mmol} / \mathrm{l}$. Thus, individuals qualifying as diabetic on one criterion but not on the other are not just borderline cases who almost reach the diagnostic level.

The probability of the disagreement in classification depended on age and body mass index. 
The WHO criteria were more likely to diagnose diabetes in lean individuals, while the ADA criteria were more likely to identify middle aged obese individuals. Thus, the disagreement does not represent a "random reclassification" but a systematic bias resulting in a change in diabetic phenotype.

\section{Screening and health economy}

Screening should rely on a valid test. In diabetes this means that it should identify individuals with chronic hyperglycaemia and a risk of developing microvascular and macrovascular complications. Given the substantial disagreement of classification between the two diagnostic criteria, the question is whether the risk is more closely associated with fasting hyperglycaemia, postprandial hyperglycaemia, or both. This can be answered only by prospective studies. Two of the three studies of microvascular complications presented by the ADA expert committee ${ }^{49}$ were cross sectional while one, in Pima Indians, was prospective.$^{30}$ For macrovascular disease the number of published similar studies is low. The recent analysis of the Paris prospective study showed that the incidence of fatal coronary heart disease was related to both fasting and 2 hour plasma glucose, but the number of events in the blood glucose intervals of interest was low. ${ }^{24}$

Epidemiological studies generally use 2 hour postload values for classification of glucose intolerance and diabetes as it is difficult to verify proper fasting. Problems with fasting will have a much larger effect on "fasting" blood glucose than on post-load values, as pointed out by the National Diabetes Data Group ${ }^{1}$ and the WHO study groups. ${ }^{2}$. If fasting values are to form the basis for future epidemiological studies of diabetes and hyperglycaemia, comparison with well standardised studies from the past 15 years will be impossible. Before such a major decision is taken the reason for changing must be very solid. The recommendations from the American Diabetes Association's expert committee were based on cross sectional studies showing that fasting plasma glucose values around 7.0 $\mathrm{mmol} / \mathrm{l}$ were associated with a risk of microvascular complications. ${ }^{4}$ We consider that prospective studies focusing also on macrovascular disease and early mortality are of more vital importance.

At present the cost of treating diabetes and its complications in Europe is estimated to be $5.8 \%$ of the total health care budget. ${ }^{8}$ Introduction of screening programmes for the general population or in high risk groups will increase the number of individuals with diagnosed diabetes, leading to increased treatment cost in these individuals. The hope is that this will in turn lead to a reduced incidence of late complications and thus reducing the treatment cost. Screening programmes for diseases such as breast cancer and cervical cancer show not only that the participation rate is much less than $100 \%$ but also that individuals at highest risk of disease may well have the lowest participation rate. ${ }^{31}$ Thus, estimation of the cost and benefit of screening for diabetes must be based on screening trials and not on speculative models, and results from one country are unlikely to be applicable to other countries and populations.
- The new diagnostic criteria for diabetes recommended by the American Diabetes Association in 1997 will increase the prevalence of diabetes from $7.2 \%$ to $7.7 \%$ in European populations

- In elderly groups with a high prevalence of diabetes the increase in prevalence would be substantially higher

- Among 17881 men and 8309 women, 1517 were classified as having diabetes according to either the American or WHO criteria

- Among these 1517 only 28\% were classified as having diabetes according to criteria of both organisations

- An analysis of existing prospective data on the prognostic impact of the new criteria should be performed before a decision is made on changing the diagnostic criteria

\section{Conclusion}

We have found that revising the diagnostic criteria as proposed by the American Diabetes Association not only changes the prevalence of diabetes in the population but also causes a rather dramatic shift of status of diabetes in individuals. It will have serious consequences not only to society and for public health but also for individuals, who will be labelled as diabetic with personal and economical consequences. On the basis of our findings and the fact that prospective data answering some of the above mentioned questions are available for reanalysis, we would like to recommend that changes in the diagnostic criteria should be undertaken only after analysis of solid prospective data, data that are available and currently being prepared.

The DECODE study (diabetes epidemiology: collaborative analysis of diagnostic criteria in Europe) was undertaken on the initiative of the European Diabetes Epidemiology Study Group (chairman Knut Borch-Johnsen; vice chairman Andrew Neil; secretary Beverly Balkau).

Investigators and study centres included in this analysis were: Denmark: Svend Larsen, Knut Borch-Johnsen, Centre of Preventive Medicine, Glostrup (Glostrup population studies); Finland: Mauno Vanhala, Pieksämäki Community Health Centre, Pieksämäki (Pieksämäki study), Aulikki Nissinen, Juha Pekkanen, Jaakko Tuomilehto, department of epidemiology and health promotion, National Public Health Institute (Helsinki east-west Finland study), Sirkka Keinänen-Kiukaanniemi, Ulla Rajala, Liisa Hiltunen, Qing Qiao, Sirkka Liisa Kivelä, department of public health science, University of Oulu (Oulu), Jaakko Tuomilehto, Pekka Jousilahti, Jaana Lindstrøm, department of epidemiology and health promotion, National Public Health Institute, Helsinki (FIN-MONICA for provinces of Kuopio and North Karelia, Turku and Helsinki areas), Marja Pyörälä, Kalevi Pyörälä, department of medicine, University of Kuopio (Helsinki policemen study), Reijo Tilvis, Sirpa Sairanen, Jaakko Tuomilehto, division of geriatrics, department of medicine, University of Helsinki (Vantaa study); France: Beverley Balkau, Eveline Eschwege, INSERM U21, Paris (Paris prospective study), Dominique Simon, INSERM U21, Paris (TELECOM); Italy: Giuseppe Gallus, Paola Garancini, epidemiology unit, S Raffaele Institute, Milan (Cremona study);

Netherlands: Robert J Heine, Jacqueline M Dekker, Institute for Research in Extramural Medicine, Vrije Universiteit, Amsterdam (Hoorn study), Edith Feskens, Institute of Public Health, Bilthoven (Zutphen study); Poland: Andrzei Pajak, department 
of clinical epidemiology and population studies, Institute of Public Health, Collegium Medicum, Jagiellonian University, Krakow (POL-MONICA study Krakow); Sweden: Hans Lithell, Bjørn Zethelius, department of geriatrics, University of Uppsala (Uppsala study); United Kingdom: Nigel Unwin, Naseer Ahmad, K George, MM Alberti, department of medicine, University of Newcastle (Newcastle heart project).

The secretariat comprised Knut Borch-Johnsen, Steno Diabetes Centre, Gentofte, Denmark; Johan Eriksson, Qing Qiao, Jaakko Tuomilehto, department of epidemiology and health promotion, National Public Health Institute, Helsinki. Data analysis was carried out by Qing Qiao and Beverley Balkau, INSERM U21, Paris, France. The writing committee comprised Knut Borch-Johnsen, Jaakko Tuomilehto, and Beverley Balkau.

Funding: Novo Nordisk, Bagsvaerd, Denmark, supported this analysis by a fellowship for Dr Qing Qiao for data analysis. Conflict of interest: None.

1 National Diabetes Data Group. Classification and diagnosis of diabetes mellitus and other categories of glucose intolerance. Diabetes $1979 ; 28: 1039-57$

2 World Health Organisation Expert Committee on Diabetes Mellitus. Second report. WHO Tech Rep Ser 1980;646:1-80.

3 Expert Committee on the diagnosis and classification of diabetes mellitus. Report. Diabetes Care 1997;20:1183-97.

World Health Organisation Study Group. Diabetes mellitus. WHO Tech Rep Ser 1985;727:1-104

5 Jarrett RJ, McCartney P, Keen H. The Bedford survey: ten-year mortality rates in newly diagnosed diabetics, borderline diabetics and normoglycaemic controls and risk indices for coronary heart disease in borderline diabetics. Diabetologia 1982;22:79-84.

6 King H, Rewers M. Global estimates for prevalence of diabetes mellitus and impaired glucose tolerance in adults. Diabetes Care 1993;16:157-77.

7 Zimmet P. Kelly West Lecture 1991. Challenges in diabete epidemiology-from the West to the rest. Diabetes Care 1992;15:232-52.

8 Kangas T, Aro S, Koivisto VA, Salinto M, Laakso M, Reunanen A. Structure and costs of health care of diabetic patients in Finland. Diabetes Care 1996;19:494-7.

9 Skarfors ET, Selinius KI, Lithell HO. Risk factors for developing non-insulin dependent diabetes mellitus: a 10 year follow up of men in Uppsala. BMJ 1991;303:755-60.

10 Hagerup L, ed. Sygdom og Sundhed, Befolkningsundersøgelserne I Glostrup UNI-C. Aarhus: UNI-C Denmark, 1987.

11 Stengard JH, Pekkanen J, Tuomilehto J, Kivinen P, Kaarsalo E, Tamminen $\mathrm{M}$, et al. Changes in glucose tolerance among elderly Finnish men during a five-year follow-up: the Finnish cohorts of the seven countries study. Diabet Metab 1993;19:121-9.

12 Feskens EJM, Kromhout D. Hyperinsulinemia, risk factors and coronary heart disease. Aterioscler Thromb 1994;14:1641-7.

13 Garancini MP, Calori G, Ruotolo G, Manara E, Izzo A, Ebbli E, et al Prevalence of NIDDM and impaired glucose tolerance in Italy: an OGTT based population study. Diabetologia 1995;38:306-13.

14 Mooy JM, Grootenhuis PA, de Vries H, Valkenburg HA, Bouter LM, Kostense PJ, et al. Prevalence and determinants of glucose intolerance in a Dutch caucasian population. The Hoorn study. Diabetes Care 1991;18:1270-3

15 Vanhala MJ, Kumpusalo EA, Pitkäjärvi TK, Takala JK. "Metabolic syndrome" in a middle-aged Finnish population. J Cardiovasc Risk 1997;4:291-5.

16 Vartiainen E, Puska P, Jousilahti P, Korhonen HJ, Tuomilehto J, Nissinen A. Twenty-year trends in coronary risk factors in North Karelia and in other areas of Finland. Int J Epidemiol 1994;23:495-504

17 Unwin N, Harland J, White M, Bhopal R, Winocour P, Stephenson P, et al. Body mass index, waist circumference, waist-hip ratio, and glucose intolerance in Chinese and Europid adults in Newcastle, UK. J Epidemiol Community Health 1997;51:160-6.

18 Rajala U, Keinänen-Kiukaanniemi S, Uusimäki A, Reijula K, Kivelä SL Prevalence of diabetes mellitus and impaired glucose tolerance in a middle-aged Finnish population. Scand J Prim Health Care 1995; 13:222-8

19 Pajak A. Insulin sensitivity and coronary heart disease risk factors in population based sample. XVII Congress of the European Society of Cardiology. Eur Heart J 1995;16(suppl): 143 .

20 Lindberg O, Tilvis RS, Strandberg TE, Valvanne J, Sairanen S, Ehnholm $\mathrm{C}$, et al. Elevated fasting plasma insulin in a general aged population: an innocent companion of cardiovascular diseases. I Am Geriatr Soc 1997;45:407-12.

21 Hitunen L, Luukinen H, Koski K, Kivela SL. Prevalence of diabetes mellitus in an elderly Finnish population. Diabet Med 1994;11:241-9.

22 Fontbonne A, Papoz L, Eschwege E, Roger M, Saint-Paul M, Simon D. Features of insulin-resistance syndrome in men from French Caribbean islands. The telecom study. Diabetes 1992;41:1385-9.

23 Pyörälä K, Savolainen E, Lehtovirta E, Punsar S, Sittanen P. Glucose tolerance and coronary heart disease: Helsinki policemen study. J Chron Dis 1979;32:45

24 Balkau B, Eschwege E, Papoz L, Richard JL, Claude JR, Warnet JM, Ducimetiere P. Risk factors for early death in non-insulin dependent diabete and men with known glucose tolerance status. BMJ 1993;307:295-9.

25 Harris MI, Klein R, Welborn TA, Knuiman MW. Onset of NIDDM occurs at least 4-7 yr before clinical diagnosis. Diabetes Care 1992;15:815-9.

26 Diabetes Control and Complications Trial Research Group. The effect of intensive treatment of diabetes on the development and progression of long-term complications in insulin-dependent diabetes mellitus. $N$ Engl Med 1993;329:977-86

27 Ohkubo Y, Kishikawa H, Araki E, Miyata T, Isami S, Motoyoshi S, et al. Intensive insulin therapy prevents the progression of diabetic microvascular complications in Japanese patients with non-insulindependent diabetes mellitus: a randomized prospective 6-year study. Diabetes Res Clin Pract 1995;28:103-17.

28 Charles MA, Balkau B, Vauzelle-Kervroedan F, Thibult N, Eschwege E Revision of diagnostic criteria for diabetes. Lancet 1996;348:1657-8.

29 Engelgau MM, Thompson TJ, Herman WH, Boyle JP, Aubert RE, Kenny SJ, et al. Comparison of fasting and 2-hour glucose and HbA1c levels for diagnosing diabetes: diagnostic criteria and performance revisited Diabetes Care 1997;20:785-91.

30 McCance D, Hanson RL, Pettitt DL, Bennett PH, Hadden DR, Knowle WC. Diagnosing diabetes mellitus-do we need new criteria? Diabetologia 1997;40:247-55

31 Kleinman JC. Who is being screened for cervical cancer. Am J Public Health 1981;71:73-6.

(Accepted 5 May 1998)
My not too long retired senior partners can recall clashing forceps and chloroform in the back streets of Burton. As I am gently eased out of time consuming obstetric care I sense a vague feeling of disquiet.

I have spent this bank holiday on call. I have been working in an urban 10000 patient practice for the past 10 years. During the 24 hours I saw 16 patients - a few more than usual perhaps, but I knew all of them or members of their family. Seeing people in their home surroundings can help build up the jigsaw pattern that makes their lives. Knowing and respecting the person makes even the diagnosis of a viral illness a pleasant interaction.

Some of the on call pleasures are more indirect-seeing the occasional fox on an early morning call, the silence of normally busy roads, the clarity of the night sky, or seeing the fading HaleBopp when driving down country roads to that patient we ought to have removed from the list some time ago.

Sometimes I cast longing eyes at the local cooperative-but for the time being we are preserving the old custom. Perhaps in the
21 st century, when we have all been pleasantly eased out of our 24 hour commitment, we will look back to on call as a quaint custom of the 1990s. I wonder if we will feel any pang of disquiet? In the sterile nine to five office based general practice of the future, we may feel that we have lost some of the magic that makes the discipline such a wonderful career.

Chris Gunstone, general practitioner, Burton upon Trent

We welcome articles up to 600 words on topics such as A memorable patient, A paper that changed my practice, My most unfortunate mistake, or any other piece conveying instruction, pathos, or humour. If possible the article should be supplied on a disk. Permission is needed from the patient or a relative if an identifiable patient is referred to. We also welcome contributions for "Endpieces," consisting of quotations of up to 80 words (but most are considerably shorter) from any source, ancient or modern, which have appealed to the reader. 